\title{
Stevia rebaudiana: a look into the future
}

\author{
Udo Kienle ${ }^{1}$
}

Published online: 14 January 2016

(C) Bundesamt für Verbraucherschutz und Lebensmittelsicherheit (BVL) 2016

Overweightness and diabetes are global epidemics and the worldwide increase of diabetes has the potential to destroy any healthcare system. One cause is the excessively high sugar content in foods, especially in soft drinks. Meanwhile, $43 \%$ of consumers have a preference for sugar-free beverages and another $26 \%$ for low sugar beverages. Finding alternatives to sugar is not just a trend it is an economic necessity.
Udo Kienle

u-kienle@uni-hohenheim.de

1 Universität Hohenheim, Garbenstr. 9, 70599 Stuttgart, Germany
The new WHO guidelines on sugar intake recommend a daily maximum of six teaspoons of $\operatorname{sugar}^{1}$ (ca. $25 \mathrm{~g}$ ) from processed foodstuffs such as cola, ketchup, frozen pizza, etc. The recommendation only refers to added sugars ("free sugars") and not to naturally occurring ones in fresh fruits, vegetables, and milk. "The risk of overweightness, obesity, and cavities will be reduced, if sugar intake is less than $10 \%$.

Percentages of sugar in various food groups indicate how much our foods contain sugar or alternative substances. ${ }^{3}$ Just to name a few: candies $97 \%$, gummy bears $77 \%$, chocolate drink powder $75 \%$, chocolate-coated marshmallow treats $65 \%$, nougat cream $60 \%$, jams $60 \%$, whole milk chocolate $56 \%$, fruit preserves $15-55 \%$, breakfast cereals and muesli (granola) bars $40 \%$, ketchup $30 \%$, fruit yoghurt $13 \%$, lemonade $12 \%$, colas $11 \%$, fruit juice $10 \%$, salad dressing $10 \%$, sausage $1 \%$.

However, the only way to reduce sugar content (and thus calories) in many foods is to use zero calorie sweeteners (Poppitt 1995). But artificial sweeteners are often viewed critically by consumers, especially in terms of presumed health risks, even though these have been ruled out by the rigorous testing process of the European Food Safety Authority (EFSA).

Consumers would prefer a natural sweetener (Breitenstein 2010), but are not satisfied with steviol

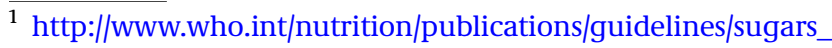
intake/en/.

2 http://www.aerztezeitung.de/panorama/article/880820/max imal-sechs-teeloeffel-who-veroeffentlicht-neue-zucker-richtlinie. html.

${ }^{3}$ http://www.vis.bayern.de/ernaehrung/lebensmittel/gruppen/ zucker.htm.
} 
glycosides, as the sluggish market penetration shows. Developing a low calorie and naturally sweet food from the Stevia rebaudiana plant itself is an obvious step. According to food law, Stevia would be a "novel food" or as a food ingredient regulated by the Novel Food Regulation.

Stevia rebaudiana, known by the indigenous Guarani people as "kaa he'e", was discovered in Paraguay in 1887 by the Swiss botanist Dr. Moises Santiago Bertoni, who learned of the species and of its sweetening properties from the Guarani. He was able to acquire a few leaves in 1894 . He classified the plant to the composite family (Asteraceae) and gave it its scientific name $S$. rebaudiana BerTons. Based on its traditional use as a natural sweetener, he realized the potential advantages this plant could offer by replacing other artificial sweeteners like saccharin, which was already being marketed as a healthy alternative for people with diabetes. Thus he predicted a successful marketing of the stevia plant based on the ancient traditional knowledge of the Guarani on the use of stevia leaves as a natural sweetener. Bertoni assumed that consuming the plant is safe: "Stevia is not only non-toxic but is in fact healthy, as long-term experiences show and as Dr. Rebaudi's studies confirm" (Bertoni 1918).

Today, in respect of the precautionary principle, sweeteners undergo safety tests before market release. It is important to ensure that sweeteners are toxicologically and physiologically harmless.

Two applications for the approval of $S$. rebaudiana as novel food had been submitted to the European Union to date [Geuns 1997, European Stevia Association (EUSTAS) 2007], without success due to the lack of studies according to the corresponding OECD guidelines for resolving toxicology issues. As a result, it is impossible for regulatory authorities to issue an approval, because they are legally bound by the provision of the European Basic Food Regulation (EC No. 178/2002). It becomes particularly problematic if applicants, for ideological reasons, are unable or unwilling to answer more detailed questions of regulatory authorities. Meanwhile, EUSTAS has been focusing on searching for proof in the EU Member States that $S$. rebaudiana had already been available to a significant degree before the Novel Food Regulation went into effect. In case of success and verification of the provided documents, S. rebaudiana would be exempt from the approval requirement in the European Union according to Article 1(2) of the Novel Food Regulation (EC No. 258/97 1997).
Apparently, EUSTAS stepped up its activities e.g. in Spain for some time in order to "flood" the markets, and in particular the German market with $S$. rebaudiana. To this end, information events are being offered with the aim of encouraging farmers to grow stevia plants. The beneficiaries are various suppliers who sell stevia seedlings at excessively high prices and attract attention with dubious promises to buy dried stevia leaves. Interested parties are lured by the implication that based on various court decisions, $S$. rebaudiana is exempt from the approval requirement in Germany and can therefore be grown and sold. These arguments are even being peddled to the authorities of EU Member States.

Ultimately, food companies have a major obligation towards consumers according to Articles 14 and 19 of Regulation 178/2002, under which the precautionary principle (Article 7) was introduced. Even if $S$. rebaudiana is exempt from the approval requirement, which does not mean that its safety is ensured and verified. Its use in foods is thus questionable and common sense dictates that it is really impermissible.

In order to confirm the safety of $S$. rebaudiana as a novel food, the University of Hohenheim and European research partners are jointly conducting toxicological studies according to OECD and GLP guidelines, with European Commission funding under the FP7 Program ("Go4Stevia-project No. 315192”). ${ }^{4}$ We expect results during the course of 2017. After years of discussion on $S$. rebaudiana, we hope for its positive ending and that consumer protection will be given respect as top priority by all stakeholders in the food chain.

\section{References}

Bertoni MS (1918) Anales Cientificos Paraguayos-Serie II, 6 de Botanica, Num. 2, Puerto Bertoni, Paraguay, pp S20-S26

Breitenstein V (2010) Consumer acceptance and consumer expectations on steviol glycosides and its use as food additive. Thesis, Department of Nutrition Science, University of Hohenheim

Poppitt SD (1995) Energy density of diets and obesity. Int J Obes Relat Metab Disord 19(Suppl 5):20-26

Regulation (EC) No. 178/2002 of the European parliament and of the Council of 28 January 2002 laying down the general principles and requirements of food law, establishing the European Food Safety Authority and laying down procedures in matters of food safety

Regulation (EC) No. 258/97 of the European parliament and of the council of 27 January 1997 concerning novel foods and novel food ingredients

\footnotetext{
${ }^{4}$ http://go4stevia.eu/.
} 